Ks. Augustyn ECKMANN*

\title{
RADOŚĆ (GAUDIUM) W NAUCZANIU ŚW. AUGUSTYNA
}

\section{POJĘCIE GAUDIUM PRZED ŚW. AUGUSTYNEM}

Łaciński termin gaudium w zależności od kontekstu może w filozofii pogańskiej odpowiadać greckim terminom: $\chi \alpha \rho \alpha^{1}, \dot{\eta} \delta o v \eta^{2}, \tau \varepsilon \dot{\varepsilon} \psi \imath \varsigma^{3}$, $\varepsilon \hat{\varphi} \varphi \rho \circ \sigma v ́ v \eta^{4}, \dot{\varepsilon} \pi \imath \theta v \mu i \alpha^{5}$. Pozytywne wzruszenia wyrażają częściej terminy

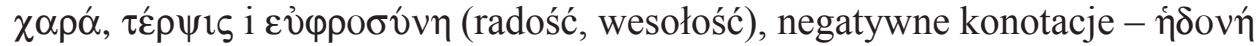
i $\dot{\varepsilon} \pi \imath v \mu i \alpha$ (łac. voluptas; używanie, przyjemność, rozkosz, przyjemność zmysłowa). Przyjemność wyjaśniano rozmaicie i częściowo kontrowersyjnie w szkołach filozoficznych. Nie tylko duchowe, ale także cielesne rozkosze mogły być oceniane pozytywnie. Łacińskie pojęcie gaudium (często z dodatkami: perpetuum - radość trwała i securum - radość beztroska, spokojna, bezpieczna) służy zwłaszcza w przedstawieniach etyki szkoły stoickiej u Cycerona i Seneki do określenia radości trwałej, bazującej na rozsądku. Stoicy cnotę definiowali jako rozsądek ( $\varphi \rho o ́ v \eta \sigma ı \varsigma)$, wiedzę ( $\dot{\pi} \pi \sigma \tau \eta \dot{\mu \eta \eta})$, rozum, i w tym kontekście występuje ratio perfecta u Seneki, który w jednym z listów definiował radość przy użyciu tego stwierdzenia, pisząc: „Tylko cnota daje radość trwałą i pewną"; czy też recta ratio u Cycerona, który w Dialogach Tuskulańskich stwierdzał:

„gdy zgodnie z rozumem dusza wzrusza się łagodnie i statecznie, wtedy nazywamy to radością, natomiast gdy dusza cieszy się daremnie i bez umiaru,

\footnotetext{
${ }^{*}$ Ks. prof. dr hab. Augustyn Eckmann - kierownik Katedry Literatury Wczesnochrześcijańskiej w Instytucie Filologii Klasycznej na Wydziale Nauk Humanistycznych Katolickiego Uniwersytetu Lubelskiego Jana Pawła II; e-mail: augustyn.eckmann@neostrada.pl.

${ }^{1}$ Por. Abramowiczówna IV 595.

${ }^{2}$ Por. tamże II 411.

${ }^{3}$ Por. tamże IV 308-309.

${ }^{4}$ Por. tamże II 377.

${ }^{5}$ Por. tamże II 235.

${ }^{6}$ Seneca, Epistula 27, 3, ed. O. Hense: L. Annaei Senecae Opera quae supersunt, III: Ad Lucilium epistularum moralium quae supersunt, Lipsiae 1907, 90: „Sola virtus praestat gaudium perpetuum, securum", thum. W. Kornatowski: Seneka, Listy moralne do Lucyliusza, Warszawa 1998, 123; por. tamże 23,$3 ; 59,2$.
} 
możemy to nazwać przesadną lub zbytnią uciechą, którą definiują jako nierozumne uniesienie duszy"'.

Termin gaudium ma również podwójne znaczenie w łacińskim przekładzie Pisma Świętego i u chrześcijańskich autorów. Może oznaczać zarówno duchową (kultową, ekstatyczną, eschatologiczną itd.) radość ludzi (też Boga), jak i cielesną przyjemność ${ }^{8}$.

\section{GAUDIUM W PISMACH ŚW. AUGUSTYNA}

Pojęcie gaudium występuje w pismach św. Augustyna 880 razy, gaudere - 1740 razy, w bezpośrednim kontekście albo jako figura etymologica, często w cytacie z J 3, 29: „gaudio gaudet propter vocem sponsi”. Uwagi świętego Augustyna na temat gaudium opierają się zarówno na tradycji filozoficznej jak i biblijnej.

1. Prawdziwa i falszywa radość. Augustyn często mówi o prawdziwej radości (verum gaudium) ${ }^{10}$, której przeciwstawia fałszywą. W Confessiones pisze na przykład o radości, która nie jest radością. Biskup wyznaje:

„Ustrzeż jednak, Boże, serce spowiadającego się Tobie sługi Twego od mniemania, jakoby każda radość, którą mógłbym odczuwać (quocumque gaudio gaudeam), prawdziwie mnie uszczęśliwiała. Jest bowiem taka radość (gaudium), której nie dostępują bezbożni, lecz doznają jej tylko ci, którzy

${ }^{7}$ Por. Cicero, Tusculanae Disputationes IV 6, 13, ed. M. Pohlenz, s. 367: „Cum ratione animus movetur placide atque constanter, tum illud gaudium dicitur, cum autem inaniter et effuse animus exultat, tum illa laetitia gestiens vel nimia dici potest, quam ita definiunt: sine ratione animi elationem”, thum. I. Śmigaj, w: Marcus Tullius Cicero, Pisma filozoficzne, t. 3, Warszawa 1961, 643.

${ }^{8}$ Por. O. Hey, Gaudium, w: Thesaurus Linguae Latinae, ed. G. Dittmann, VI/2, Leipzig 19251934, 1712, 53-63; O. Michel, Freude, RACh VIII 371-416; L. Cignelli, Il tema del „Christo gioia” nella Chiesa patristica, w: Studia Hierosolymitana, III: Nell'Ottavo centenario francescano (11821982), ed. G.C. Bottini, Jerusalem 1982, 169-192; R. Hauser, Lust, Freude II, w: Historisches Wörterbuch der Philosophie, ed. J. Ritter, V, Basel 1980, 555-558.

${ }^{9}$ Augustinus, Confessiones 4, 15, 27, NBA 1, 106; 11, 8, 10, NBA 1, 376; por. tenże, Epistula 266, 3; In Joannis Evangelium tractatus 13, 10. 12. 14. 16; 14, 2n; 19, 14; 57, 3; Enarrationes in Ps. $35,9.18 ; 38,4 ; 50,13 ; 131,14 ; 133,1 ; 139,15$.

${ }^{10} \mathrm{~Np}$. w Confessiones 6, 9n., Augustyn porównuje własną radość z radością żebraka, którego spotkał na ulicach Mediolanu. Augustyn przygotowywał się do wygłoszenia mowy na cześć cesarza. Miał w niej wiele nakłamać i zebrać rzęsiste oklaski od słuchaczy. Wielką czuł tremę i bardzo przygotowywał się do tego wystąpienia. Wtedy właśnie idąc jedną z uliczek Mediolanu, zobaczył obdartego żebraka, który śmiał się i żartował. Doznawał radości ziemskiego szczęścia (laetitiam temporalis felicitatis). Nie było to szczęście prawdziwe (verum gaudium), ale Augustyn też nie był szczęśliwy, wykształcenie nie czyniło go szczęśliwym, on dopiero przedzierał się do szczęścia za cenę wielkich wysiłków, ale to jego szczęście było jeszcze bardziej fikcyjne niż żebraka, który zebrał trochę grosza, kupił sobie wina i ono chwilowo go uszczęśliwiło. 
Cię czczą ze względu na Ciebie samego, ci, których radością Ty sam jesteś (quorum gaudium tu ipse es). To właśnie jest szczęściem: radowanie się w dążeniu ku Tobie (gaudere ad te), radowanie się Tobą (de te), radowanie się ze względu na Ciebie (propter te). To jest prawdziwym szczęściem i nie ma szczęścia innego. Ci, którzy cokolwiek innego uważają za szczęście, dążą do takiej radości, która nie jest prawdziwa (aliud sectantur gaudium neque ipsum verum). Ale nawet ich wola nigdy się nie odwraca od jakiegoś wyobrażenia radości (imagine gaudii)" $"$.

Te dwa rodzaje radości różnicuje Augustyn pod względem ich stosunku do zainteresowania się jakimś przedmiotem i ich poziomem jakości, charakteryzując je często za pomocą abstrakcyjnej pary przeciwnych sformułowań: in domino... in saeculo ${ }^{12}$, gaudia veritatis cum gaudiis vanitatis ${ }^{13}$, carnalia... aeterna ${ }^{14}$, terrena ... aeternis ${ }^{15}$, immundo ...vero ${ }^{16}$ itd. Czasem Augustyn odgranicza gaudium prawdziwe od pojęcia wesołości laetitia ${ }^{17}$, czy jeszcze mocniej odróżniając gaudere od gestire (skakać z radości, radować się, namiętnie pragnąć) ${ }^{18}$. Mówi też Augustyn o gaudium Babylonium ${ }^{19}$ lub o terrena series generationum, które lgną do terrena gaudia ${ }^{20}$. Prawdziwa radość jest natomiast czysto duchowa (gaudium spiritale) ${ }^{21}$, nie jest osiagalna zmysłami ${ }^{22}$, zjawia się, kiedy człowiek nie kieruje swych działań w kierunku dóbr doczesnych, ale na życie wieczne: futuri saeculi gaudium ${ }^{23}$. Augustyn naucza:

„Cieszymy się (congaudemus) z waszej licznej obecności, albowiem liczniej

${ }^{11}$ Augustinus, Confessiones 10, 22, 32, NBA 1, 328, thum. Z. Kubiak: Święty Augustyn, Wyznania, Warszawa 1987, 242n.

${ }^{12}$ Tamże 10, 22, 32, NBA 1, 328.

${ }^{13}$ Tenże, In Joannis Evangelium tractatus 7, 24, NBA 24/1, 186.

${ }^{14}$ Tamże 28, 8, NBA 24/1, 642.

${ }^{15}$ Tenże, Enarrationes in Ps. 57, 11, NBA 26, 214, 216.

${ }^{16}$ Tamże 125, 6, NBA 28, 120.

${ }^{17}$ Tenże, In Joannis Evangelium tractatus 60, 4, NBA 24/2, 1112; por. tamże 123, 5; Epistula 104, 10; De civitate Dei 14, 8. Na równi są postawione pojęcia: gaudium i laetitia (częściowo według Ps 51(50), 10) w Confessiones 4, 27; In Joannis Evangelium tractatus 57, 3; Sermones 45, 10; 104, 5; Enarrationes in Ps. 93, 24.

${ }^{18}$ Tenże, De sermone Domini in monte 2, 81, NBA 10/2, 276.

${ }^{19}$ Tenże, Enarrationes in Ps. 136, 5, NBA 28, 402; por. tamże 136, 1 n.

${ }^{20}$ Tenże, De civitate Dei 15, 15, NBA 5/2, 414.

${ }^{21}$ Tenże, De Genesi contra Manichaeos 2, 9, 12, NBA 9/1, 136; por. tenże, Enarrationes in Ps. 137, 4; De sermone Domini in monte 2, 40; In Joannis Evangelium tractatus 7, 1; De consensu evangelistarum 2, 63.

${ }^{22}$ Por. tenże, In Joannis Evangelium tractatus 35, 9; 43, 16.

${ }^{23}$ Tenże, Epistula 122, 1, NBA 21, 1238: „Et si deliciae seculi huius breves et sordidae, sic amantur; quando vehementius futuri seculi gaudia pura et infinita quaerenda sunt". W liście 264, 2 Augustyn mówi też o radości w tym życiu: „Gaudium vero quod percipimus quando aliqui ex eis correcti in melius commutantur, et sanctorum societati copulantur, nulli gaudio in hac vita comparari potest" (PL 33, 1085). 
niż mogliśmy się spodziewać, przybyliście gorliwie. To nas raduje i pociesza (laetificat et cosolatur) we wszystkich pracach i niebezpieczeństwach tego życia; wasze umiłowanie Boga, pobożna gorliwość, niezachwiana nadzieja i żarliwość ducha. [...] A jeśli dziś nieco dłużej was zatrzymaliśmy, uczyniliśmy to celowo, aby niebezpieczne godziny przeminęły, iż kończy się już ich czas marności. My zaś, bracia, będąc nasyceni zbawiennymi pokarmami, tak pozostały czas przepędźmy, abyśmy dzień niedzielny spędzili uroczyście, na duchowych radościach (in gaudiis spiritalibus), i porównywali radości, jakie daje prawda (gaudia veritatis), z radościami tego, co jest marnością (gaudia vanitatis). Jeśli nas przeraża ich postępowanie, bolejemy; jeżeli bolejemy, modlimy się; jeśli się modlimy, będziemy wysłuchani; a jeżeli będziemy wysłuchani, to ich pozyskamy"24.

2. Radość wynikająca z nadziei i radość rzeczywista. Augustyn rozróżnia „dwa czasy, to jest czas pracy i troski, drugi radości i wolny od trosk” 25 . W tym życiu jest możliwa radość, która wynika z nadziei (gaudium de spe) ${ }^{26}$ zgodnie z Listem do Rzymian 15, 13: spe gaudentes ${ }^{27}$. Obecna radość nie jest rzeczywista, ale płynie z nadziei ${ }^{28}$. Radość rzeczywista ( gaudium de re) spełnia się dopiero w życiu przyszłym, wtedy wielka i doskonała będzie radość, pełnia radości, która nie karmi się mlekiem, lecz żywi się pokarmem stałym ${ }^{29}$. Takie życie w radości prowadzą aniołowie i święci ${ }^{30}$ oraz ludzie znajdujący się już po drugiej stronie życia, będący podobni do aniołów ${ }^{31}$.

${ }^{24}$ Tenże, In Joannis Evangelium tractatus 7, 1. 24, NBA 24/1, 154 i 186, PSP 15/1, 113 i 132.

${ }^{25}$ Tenże, De diversis quaestionibus 83, 81, 3, NBA 6/2, 252: „[...] duo tempora, id est, unum laboris et sollicitudinis, alterum gaudii et securitatis".

${ }^{26}$ Tenże, Enarrationes in Ps. 32(2), 28, NBA 25, 610: „[...] implevit nos gaudio spei”; por. tamże 48(2), 5, NBA 25, 1230: ,[...] videte vocem sperantis de futuro"; 48(2), 5, NBA 25, 1232 : ,$[\ldots]$ gaudium non est quasi [...]”; 147, 6, NBA 25, 814 .

${ }^{27}$ Tenże, De Trinitate 1, 17, NBA 4, 32: „Haec enim nobis contemplatio promittitur actionum omnium finis atque aeterna perfectio gaudiorum".

${ }^{28}$ Por. tenże, Enarrationes in Ps. 145, 2, NBA 28, 726: „[...] gaudium nondum de re, sed de spe”; zob. tamże 123, 2; NBA 28, 60 i 62: „Gaudium ergo nostrum, fratres, nondum est in re, sed iam in spe"; tenże, Sermo Mai 94, 7, MA I, 339. W De Trinitate 10, 17 Augustyn definiuje frui jako „uti cum gaudio, non adhuc spei, sed iam rei”.

${ }^{29}$ Por. tenże, Sermones 21, 1, NBA 19, 392. Biblijna metaforyka pełnej radości (plenum/impletum gaudium, implere gaudio) zgodnie z Ps 125, 2; J 3, 29; 15, 11; 16, 24; 17, 13 i Rz 15, 13 występuje bardzo często w pismach św. Augustyna, zob. np. In Joannis Evangelium tractatus 83, 1; 102, 2; 107, 8; Enarrationes in Ps. 125, 5n.; Epistula 41, 1; 150; 170, 10; 179, 4.

${ }^{30}$ Por. tenże, Sermones 4, 4, NBA 19, 30:, ,...] vivunt [...] angeli in gaudio"; De catechizandis rudibus 24,45 , NBA 7/2, 274: ,[...] gaudio vitae aeternae, quam sancti accepturi sunt”; De sancta virginitate 27, NBA 7/1, 110: ,[...] gaudium virginum Christi”.

${ }^{31}$ Por. tenże, Sermo Dolbeau 21, 15, NBA 35/2, 430: „Gaudium nostrum non erit nisi in patria, cum angelis aequati fuerimus". 
3. Radość w życiu szczęśliwym i w kontemplacji. Prawdziwa radość powstaje, kiedy człowiek osiąga najwyższy cel, co jest zgodnie z filozoficzną terminologią określone jako życie szczęśliwe (beatitudo) albo najwyższe dobro (bonum, finis) ${ }^{32}$ :

„Na tym polega szczęśliwe i spokojne życie człowieka, by wszelkie jego poruszenia były zgodne z rozumem i prawdą. Nazywa się też je radościami czystymi i dobrymi oraz miłością świętą"33.

Te możliwe już w tym życiu doświadczenia przeżywania radości opisuje Augustyn w kontekście kontemplacji (contemplatio) ${ }^{34}$, najczęściej w platonizujących tekstach. Contemplatio następuje po nawróceniu serca (conversio cordis) i kieruje się ku życiu szczęśliwemu (vita beata):

„Dokonuje się w modlitwie nawrócenie serca do Tego, który zawsze jest gotowy dać to, co daje, o ile tylko tego pragniemy. A w tymże nawróceniu dokonuje się oczyszczenie oka wewnętrznego, gdy wykluczamy wszystko to, co pragnęliśmy docześnie, aby bystrość prostego serca mogła znieść jasne światło promieniujące w Boski sposób bez żadnego zachodu lub zaćmienia. Nie tylko znieść, ale również trwać w nim, bez boleści, a nawet z niewysłowioną radością, dzięki której doskonali prawdziwie i szczerze życie błogosławione" ${ }^{35}$.

Wśród utrapień zwykłego dnia gaudia cotidiana prowadzą do najwyższego celu - do radości bez końca (gaudium sine fine) ${ }^{36}$. Radość w eschatologicznej

${ }^{32}$ Tenże, De libero arbitrio 1, 29, NBA 3/2, 194; por. tenże, Confessiones 10, 33n., NBA 1, 345n; De quantitate animae 33, 76, NBA 3/2, 122; Epistula 118, 3, 13, NBA 21, 1146.

${ }^{33}$ Tenże, De Genesi contra Manichaeos 1, 31, NBA 9/1, 98: ,[...] et haec est hominis vita beata atque tranquilla, cum omnes motus eius rationi veritatique consentiunt; et vocantur gaudia, et amores sancti, et casti et boni”, tłum. J. Sulowski: Św. Augustyn, Pisma egzegetyczne przeciw manichejczykom; Przeciwko manichejczykom komentarz do księgi Rodzaju; Niedokończony komentarz słowny do księgi Rodzaju, Komentarz słowny do księgi Rodzaju, PSP 25, Warszawa 1980, 41; por. F. Drączkowski, Pokój serca, Pelplin 1999, 137-150.

${ }^{34}$ Augustinus, Enarrationes in Ps. 26(2), 9, NBA 25, 368: ,[...] gaudium contemplandi [...]”.

${ }^{35}$ Tenże, De sermone Domini in monte 2, 3, 14, NBA 10/2, 198: „Fit ergo in oratione conversio cordis ad eum qui semper dare paratus est, si nos capiamus quod dederit, et in ipsa conversione purgatio interioris oculi, cum exccluduntur ea quae temporaliter cupiebantur, ut acies simplicis cordis ferre possit simplicem lucem divinitus sine ullo occasu aut immutatione fulgentem, nec solum ferre sed etiam manere in illa non tantum sine molestia sed etiam cum ineffabili gaudio, quo vere ac sinceriter beata vita perficitur"; por. tenże, De Trinitate 1, 17, 31; Sermones 53, 6.

${ }^{36}$ Tenże, Enarrationes in Ps. 93, 24, NBA 27, 292: „Beati, qui habitant in domo tua; in saecula saeculorum laudabunt te (Ps 83, 5). Haec est requiem sempiterna: sine fine erit requiem ista, sine fine erit gaudium hoc, sine fine erit laetitia ista, sine fine erit incorruptio, vitam aeternam habebis". 
wizji jest niewyrażalna - ineffabile $e^{37}$ i nie dająca się opowiedzieć - inenarra$b_{i l e} e^{38}$. Język jest zbyt ubogi, by opisać tę radośćc 39 .

4. Radość w Bogu i w lączności z Nim. Prawdziwa radość spełnia się w Bogu i przy Bogu ${ }^{40}$, taka radość jest trwała: solidum ${ }^{41}$, certum et solidum ${ }^{42}$. Posługując się metonimią określa biskup Augustyn Boga (tak samo Chrystusa) jako gaudium:

„Jak to wytłumaczyć, Panie Boże mój, skoro przecież Tyś sam dla siebie radością wiekuistą i zawsze jesteś otoczony istotami, które się tobą radują"³.

Wyprowadzenie ludzi z bólu, może stanowić okazyjnie radość (gaudium) ${ }^{44}$ lub do radości prowadzić ${ }^{45}$. Według J 15, 11 i Augustyńskiej interpretacji w In

${ }^{37}$ Tenże, De sermone Domini in monte 2, 3, 14, NBA 10/2, 198; por. tenże, Enarrationes in Ps. 44,$8 ; 85,17$.

${ }^{38}$ Tenże, Enarrationes in Ps. 26(2), 12, NBA 25, 372. W tym sensie czyta Augustyn w De peccatorum meritis et remisssione $(1,41, \mathrm{NBA} 17,72)$ fragment $1 \mathrm{P} 1,8:,[\ldots]$ in quem modo non videntes creditis; quem cum videritis exultabitis gaudio inerrabili et honorato"; por. tenże, In Joannis Evangelium tractatus 86, 1; Contra epistolam Pelagiani 3, 17; Epistula 147, 8 (Wulgata ma inny tekst: ,[...] in quem nunc non videntes creditis: credentes autem exultabitis laetitia inerrabili, et glorificata").

${ }^{39}$ Por. tenże, Enarrationes in Ps. 80, 3, ed. P.E. Dekkers - I. Fraipont, CCL 39, Turnholti 1956, 1122: ,[...] ex abundantia gaudiorum, cui verba sufficere non possunt, in iubilationem solet erumpere: Iubilate Deo Iacob"; zob. tamże 32(1), 8; 88(1), 16; 94, 3.

${ }^{40}$ Por. tenże, De vera religione 55, 111, NBA 6/1, 154: „Iusti autem homines, et in uno Deo habentes omnia gaudia sua”; In Joannis Evangelium tractatus 10, 13, NBA 24/1, 250: „Simus in humilitate cordis semper, et gaudium nostrum penes ipsum sit"; częściej z powołaniem się na Mt 25, 23 (,,[... [intra in gaudium Domini tui”): De vera religione 106; De sermone Domini in monte 1, 29; Confessiones 2, 18; 9, 25; De Trinitate 1, 31; Epistulae 140, 57, 80; Sermones 319, 2.

${ }^{41}$ Tenże, Confessiones 12, 16, 23, NBA 1, 424.

${ }^{42}$ Tenże, De beata vita 2, NBA 3, 182: „[...] ad certa et solida gaudia”. Częściej łączy Augustyn gaudium z cytatem z J 16, 22, ,[...] et gaudebit cor vestrum, et gaudium vestrum nemo tollet/auferet a vobis", np. De Trinitate 1, 20; In Joannis Evangelium tractatus 101, 3, 5; Sermones 210, 7.

${ }^{43}$ Tenże, Confessiones 8, 8, NBA 1, 224, 226 : „Quid est hoc, Domine Deus meus, cum tu aeternum tibi, tu ipse sis gaudium, et quaedam de te circa te semper gaudeant?”, thum. Z. Kubiak, 169; por. tamże 7, 11; 10, 32; 12, 23; tenże, In Joannis Evangelium tractatus 101, 3; Enarrationes in Ps. 84, 8. 10; zob. F. Drączkowski, Aby radość wasza była petna, Pelplin 2012.

${ }^{44}$ Por. Augustinus, Quaestiones Evangeliorum 2, 18, NBA 10/2, 354, 356: „Ieiunium aut in tribulatione est aut in gaudio: in tribulatione ad propitiandum Deum pro peccatis, in gaudio vero, cum tanto minus delectant carnalia, quanto spiritalium maior sagina est”; zob. tenże, Enarrationes in Ps. 101(1), 2; Speculum 46.

${ }^{45}$ Por. tenże, Enarrationes in Ps. 26(2), 14, NBA 25, 374: „Transiet oratio, succedet laudatio; transiet fletus, succedet gaudium"; zob. tamże 79, 7; tenże, Epistula 194, 1; często z cytatem z Ps 29, 12: ,[...] convertisti planctum/luctum meum in gaudium mihi”, także z Ps 125, 5; tenże, Confessiones 8, 30; Contra Faustum 12, 36; Enarrationes in Ps. 29(1), 12; 107, 1; Sermones 163, 3; 326, 1; 337, 2, tenże Confessiones 8, 8, NBA 1, 224: ,[...] ubique maius gaudium modestia maiore praeceditur (większa przykrość poprzedza tym większą radość)", tamże 8, 7; tenże, Sermo Denis 17, 9. 
Joannis Evangelium tractatus 83, 1 ludzie cieszą się tym, że są chrześcijanami i to napełnia ich radością Chrystusa. Ta radość wyraża się w śpiewie ${ }^{46}$, W chwale Boga ${ }^{47}$ oraz radości świąt Bożego Narodzenia ${ }^{48}$.

$\mathrm{Z}$ wielkim entuzjazmem i liryzmem mówi Augustyn o radości dziewic Chrystusa:

„[...] radość dziewic Chrystusa, z Chrystusa, w Chrystusie, po Chrystusie, przez Chrystusa, z powodu Chrystusa"49.

Bogaty okres retoryczny wyraża radość dziewic. Jest nią Chrystus. Za pomocą sześciu przyimków (de, in, cum, post, per, propter) Augustyn wskazuje na więź łączącą dziewice z Chrystusem. Chrystus jest przedmiotem, początkiem, współuczestnikiem, wzorem, przyczyną i celem ich radości. Dziewice idą za Chrystusem, naśladują Go przez urzeczywistnianie ewangelicznych błogosławieństw, a jeszcze wyraziściej przez stan dziewictwa ${ }^{50}$. Podkreślając rację mistyczną dziewictwa, Augustyn wzruszająco woła:

„Idźcie więc, o święci Boga, chłopcy i dziewczęta, mężczyźni i kobiety, bezżenni i niezamężne. Biegnijcie wytrwale do celu"s51.

Podsumowując można stwierdzić, że uwagi św. Augustyna na temat radości (gaudium) opierają się zarówno na tradycji filozoficznej, jak i biblijnej. Biskup odróżnia prawdziwą radość od fałszywej. Te dwa rodzaje radości różnią się przedmiotem i jakością. Prawdziwa radość jest czysto duchowa (gaudium spiritale), ukierunkowana ku życiu wiecznemu, podczas gdy radość fałszywa zwraca się ku dobrom doczesnym. W tym życiu jest możliwa radość, która wynika z nadziei (gaudium de spe), radość rzeczywista (gaudium de re) spełni się dopiero w życiu przyszłym. Radości codzienne, będące zgodne z rozumem i prawda, prowadzą do radości wiecznej. Prawdziwa radość powstaje, kiedy człowiek osiaga najwyższy cel. Spełnia się ona w Bogu i jest trwała.

${ }^{46}$ Por. tenże, Enarrationes in Ps. 7, 19, Sermo Denis 17, 9.

${ }^{47}$ Por. tenże, Sermones 252, 9, NBA 32/2, 760: ,[...] totum gaudium erit Alleluja, id est «laus Dei»"; zob. tamże 252, 12.

${ }^{48}$ Por. tenże, Sermones 188, 4, NBA 32/1, 34.

${ }^{49}$ Tenże, De virginitate 27, 27, NBA 7/1, 110: ,[...] gaudium virginum Christi, de Christo, in Christo, post Christum, per Christum, propter Christum".

${ }^{50}$ Por. tamże 28, 28 - 29, 29, NBA 7/1, 112-114.

${ }^{51}$ Tamże 27, 27, NBA 7/1, 110: „Pergite itaque sancti Dei, pueri ac puellae, mares ac feminae, caelibes et innuptae; pergite perseveranter in finem". 


\section{JOY (GAUDIUM) IN THE TEACHING OF ST. AUGUSTINE}

\section{(Summary)}

Notes of St. Augustine on joy (gaudium) are based on both the philosophical tradition and the Bible. Bishop distinguishes the true joy from the false one. These two types of joy differ in the subject of happiness and its quality. True joy is purely spiritual (gaudium spiritale), aimed to eternal life, while the false joy turns to the worldly possessions. In this life is possible the joy that comes from hope (gaudium de spe), a real joy (gaudium de re) meet only in the future life. Everyday joy, which is consistent with reason and truth, leads to the eternal joy. The true joy arises when one attains the highest goal. It meets in God and is permanent. 